\title{
Nutritional Status and Risk Factors of Malnutrition among 0-24 Months Old Children Living in Mezam Division, North West Region, Cameroon
}

Ngondi Judith Laure ${ }^{1 *}$, M'bobda Momdjo Christelle ${ }^{1}$, Lucy Bilkha², Mbouobda Hermann Desire ${ }^{2}$ and Oben Julius ${ }^{2}$

${ }^{1}$ Department of Biochemistry, Faculty of Science, the University of Yaounde, Yaounde, Cameroon

${ }^{2}$ Higher Teacher's Training College, The University of Bamenda, Bamenda, Cameroon

\begin{abstract}
Introduction: Childhood malnutrition especially under nutrition is one of the most frequent causes of child morbidity and mortality. The consequences of malnutrition are more apparent in adulthood; it results in poor physical development and diminished cognitive abilities.

Objective: To evaluate the nutritional status of supposedly healthy children aged 0 to 2 years old, attending vaccination clinics in Mezam division, North West Region, Cameroon.

Methods: It was a descriptive survey using structured questionnaires, which covered socioeconomic and demographic information, breastfeeding practices, socio-cultural and economic factors and anthropometric data. Anthropometric measurements were taken (weight, height, head circumference). The total number of children was 990 ( 561 girls and 429 boys) all from diverse ethnic groups and backgrounds. The anthropometric indicator used was the weight-for-age. The nutritional status of these children was evaluated with respect to a number of factors which are: age range, the sex of the children, milk feeding, socio-economic and demographic factors. The results obtained were expressed in percentages.

Results: Comparison of the growth patterns of the study population with that of the NCHS references revealed that none of the children grew exactly according to the NCHS references. The prevalence rate of both under nutrition and over nutrition among the 0-2 year's old children living in Mezam division was high. Children aged 0 to 6 months were more affected by under nutrition while those aged 6-12 months were more affected by over nutrition. Risk factors of under nutrition in these infants were as a result of factors such as: Nature of parents' profession, parents' educational level, inappropriate child feeding practices such as exclusive breastfeeding practiced incorrectly and mixed feeding started too early.
\end{abstract}

Conclusion: The study revealed a high prevalence rate of both under nutrition and over nutrition among children aged 0-2 year's old living in the Mezam division.

Keywords: Nutritional status; Malnutrition; Children; Mezam Division; North West Region

\section{Introduction}

Protein Energy Malnutrition (PEM) represents one of the main public health problems throughout the world, especially in developing countries. The World Health Organization estimates that approximately 150 to 200 million pre-school children $(<5$ years) in developing countries are underweight and stunted, respectively. Interestingly, less than 5 mortality is expected to increase in Sub-Saharan Africa where the prevalence of childhood malnutrition is about $41 \%$ compared to other regions of the developing world [1]. This current trend of malnutrition and childhood mortality in Sub-Saharan Africa is far from that of the Millennium Development Goals (MDG) [2]. Malnutrition, especially micronutrient deficiency, adversely affects health, cognition, motor development, and general growth of children 5 years of age and younger [3]. Malnutrition in early childhood is also associated with functional impairment in adult life, reduced work capacity, and decreased economic productivity of the individual [4]. Malnourished children have also been found to score lower on the Bayley Scales of Infant Development compared to their healthy counterparts [5].

Environmental and social factors as well as hygiene habits are important risk factors associated with nutritional status, as reported by Ferrari et al. [6]. Previous studies have also linked childhood malnutrition with maternal education and employment, family support and social network $[7,8]$. Others have also associated childhood malnutrition with a number of biomedical characteristics, such as birth interval (preceding and following each child birth), maternal age at child birth, child's age and gender [9].

Although there is a gradual overall reduction in the prevalence of childhood malnutrition in some Regions of Cameroon, [10], the Eastern and Northern Regions of the country still have a higher prevalence of childhood malnutrition in general; with the Far North region having a critical rate [11]. In Cameroon the prevalence of children under five years of age with a weight deficit for their age (underweight) was $19.3 \%$ in 2006 (11). The prevalence of children under five years of age with a weight deficit for their height (wasted) was 6\% in Cameroon [11]. Knowing that the prevalence of childhood malnutrition is disproportional according to the region and socio-economic status of the family $[12,13]$, it is therefore important to evaluate the prevalence of malnutrition and identify and understand the risk factors of malnutrition among children from semi-rural farming communities.

*Corresponding author: Ngondi Judith laure, Department of Biochemistry, Faculty of Science, The University of Yaounde I, Yaounde,Cameroon; Tel: 0023773290624 E-mail: ngondij udithl@hotmail.com

Received August 11, 2014; Accepted September 30, 2014; Published october 01,2014

Citation: Laure NJ, Christelle MM, Bilkha L, Desire MH, Julius O (2014) Nutritional Status and Risk Factors of Malnutrition among 0-24 Months Old Children Living in Mezam Division, North West Region, Cameroon. J Nutr Disorders Ther 4: 150. doi:10.4172/2161- 0509.1000150

Copyright: ( 2014 Laure NJ, et al. This is an open-access article distributed under the terms of the Creative Commons Attribution License, which permits unrestricted use, distribution, and reproduction in any medium, provided the original author and source are credited. 
This study therefore evaluated the nutritional status and identified the risk factors of malnutrition among 0-2 years old children living in Mezam division, North West Region of Cameroon.

The specific objectives consisted in:

- Evaluating the prevalence of malnutrition in the children with respect to age range and gender.

- Evaluating the prevalence of malnutrition in the children with respect to the socio-demographic status of their parents.

- Evaluating the prevalence of malnutrition in the children with respect to the types of milk feeding of the children.

The stated hypothesis was that 0 to 2 years old children from semirural or farming communities are at a greater risk of malnutrition in early childhood.

\section{Study Area and Period}

This study (survey) which took place from April to May 2014 was carried out at the District Hospital-Bambili, District Hospital-Bambui, Distict Hospital-Nkwen and Regional Hospital-Bamenda. Bamenda, Bambui and Bambili are localities found in Mezam Division of the North West region of Cameroon. Bambili and Bambui are found in Tubah Sub division. The Regional Hospital-Bamenda, at the time was situated about 10 metres away from "Hospital Round-about" in the premises of the Delegation of Public Health. The District HospitalNkwen is situated opposite the "Amour Mezam" park in Nkwen. The District Hospital- Bambui is situated about 20 metres before the Catholic seminary (going from Bambili). The District Hospital-Bambili is situated on the right hand corner of the road, about 20 metres from "Three corners" Bambili (on your way to Bambui).

\section{Source and study population}

1059 (264 per hospital) children aged 0 to 24 months who attended the District Hospital-Bambili, District Hospital-Bambui, Distict Hospital-Nkwen and Regional Hospital-Bamenda made up the source population and the study population.

\section{Inclusion and exclusion criteria}

Inclusion criteria: All supposedly healthy children from 0 to 2 years of age who attended the district hospitals were considered.

Exclusion criteria: For the exclusion criteria, all children who were more than 2 years old were not considered. Also, children whose questionnaires had not been completely filled were not considered.

\section{Sample size determination}

The sample size was determined using the following formula: $\mathrm{N}=$ $\left(\mathrm{Z}^{2} \mathrm{P}(1-\mathrm{P})\right) / \mathrm{m}^{2}$ where $\mathrm{P}$ is the prevalence of under nutrition among under five years children in Cameroon evaluated at 19.3\% (UNICEF 2006); $\mathrm{t}=$ Confidence interval at $95 \%(\mathrm{Z}$ - value of 1,96$) ; \mathrm{m}=$ marginal error at $5 \%$ and $\mathrm{N}$ the sample size [14]. We obtained a sample size value of $n=240$ children.

An adjustment for non-response (10\% contingency). Finally we obtained a sample size of $(240+24)=264$. This number was multiple by the design effect 4 and the final sample size was 1059.

\section{Sampling techniques}

The study was carried out in four different hospitals: Bambili District Hospital; Bambui District Hospital; The District Hospital, Nkwen and the Regional Hospital. From each of these hospitals, all children aged 0-24 months and their mothers or caregivers who attended the district hospitals during the two months study period were retained to participate in the study.

\section{Study variables}

Dependent variable: The dependent variable for this study was the anthropometric index weight-for-age (W/A) which indicates the level of underweight.

Independent variables: The independent variables were: child's and mother's age, sex, education of the mother and father, type of milk feeding, parents' occupation and marital status of parents.

\section{Operational Definitions}

Percentage of the median for weight: The percentage of the median for weight is the ratio of the weight of the child to the median weight of the NCHS/WHO reference for the same age for the specific sex, expressed as a percentage.

Weight-for-age: Low weight-for-age index of a child identifies the condition of being underweight, for a specific age with respect to the NCHS/WHO reference.

Underweight: The child is said to be underweight when his percentage weight-for-age is less than the $89 \%$ Gomez classification of malnutrition using the NCHS/WHO reference as standard [27].

\section{Parents' revenue}

Refers to the mother's job and the father's job combined.

\section{Milk feeding}

Refers to feeding the child only either with breast milk, artificial milk or both from birth to six months of age.

\section{Data collection procedure}

Data collection lasted a period of 2 months, given that these measurements were done once a week on the respective vaccination days (Mondays for District hospital Nkwen, District hospital Bambui and Regional hospital Bamenda; Wednesdays for District hospital Bambili). These data and anthropometric measures were collected by trained nurses and trained personnel recruited from the various localities. The collection of anthropometric data through measurements of the height, weight and head circumferences of the children was employed.

Data were gathered by a combination of structured questionnaires. The mother of each child was interviewed in order to collect all the necessary informations. The structured questionnaires covered demographic informations, breastfeeding practices, socio-cultural and economic factors, information on the child's health and anthropometric data. Data were collected as follows: In 2 stages at Bambili, in 3 stages at Bambui, in 2 stages at the preventive hospital and once at the district hospital Nkwen in Bamenda.

\section{Identity of the child}

Information about the age of each child was given by the mother of the child and verified from their vaccination booklets. These booklets also provided informations on the names and sexes of the children.

\section{Anthropometric data}

The anthropometric measures were collected as recommended by 
the WHO method [27]. The anthropometric measure (weight) of the children was measured in order to determine their nutritional status. The nutritional status was determined using the percentage of the median method. The percentage of the median was calculated with the child's weight and age using the NCHS/WHO reference values. These enabled to obtain the percentage weight-for-age (\%W/A) index. The value obtained for each child was then compared to the Gomez Classification of Malnutrition to evaluate whether the children were overweight, normal, mildly, moderately or severely malnourished as follows: Percentage of reference WFA: >110\% (Overweight); 90-110\% (Normal); 75-89\%: (Grade I: mild malnutrition); 60-74\%: (Grade II: moderate malnutrition); and $<60 \%$ : (Grade III: severe malnutrition) [15] .

\section{Length/Height}

Length of children below 24 months was measured from the crown to the heel using a paediatric measuring board to the nearest $0.1 \mathrm{~cm}$. The length was measured without shoes. The measurement was only taken if the head was the same level with the headboard and the end of the measuring mat or board was against a flexed heal. The measurement was taken at eye level. Height whereas was measured for children 24 months old. It was measured with a stadiometer (portable height measuring $2 \mathrm{~m}$ tape). The child stood without shoes, with heels together, arms to the sides, legs straight, shoulders relaxed and head in the Frankfort horizontal plane (looking straight ahead). Heels, buttocks, scapulae (shoulder blades) and back of the head were against the vertical surface of the stadiometer. The height was taken twice and recorded to the nearest $0.1 \mathrm{~cm}$.

\section{Weight}

The weights of the babies (0-1year) were measured using a $25 \mathrm{~kg}$ scale to the nearest $0.1 \mathrm{~kg}$; the babies were undressed and wore minimal clothing. The child was placed on the scale so that the weight was evenly distributed. The measurement was taken to the nearest $10 \mathrm{~g}$ while the child was lying still. The average of two weights was recorded numerically on the record sheet. Those aged 1 to 2 years were measured using a Health Scale Mic balance. The scale was placed on a flat, hard surface that allowed the child to stand securely. The child stood still in the middle of the scale's platform without touching anything and with the weight equally distributed on both feet. The child was weighed with light clothing and without shoes. The average of two weights was recorded numerically on the record sheet to the nearest $0.01 \mathrm{~kg}$.

\section{Head circumference}

It was measured using a non-stretch measuring tape, which was placed around the head and the largest circumference measured to the nearest $0.1 \mathrm{~cm}$. Generally, measurement of the head circumference in babies provides clues about brain growth and development.

\section{Child's health state}

The Mother was asked whether her child was sick and if the answer was no, she was asked to recall the last time her child was sick and from which illness the child had suffered and these informations were recorded. Informations concerning the child's immunization state were gotten from the child's vaccination booklet.

\section{Data quality management}

Questionnaires were pre-tested on $10 \%$ of the sample size for flow of questions and for validity. Questions that were not well structured were restructured and time spent was recorded. All equipment were calibrated and ensured that they were in good states.

\section{Data processing and analysis}

Data from the district hospitals were entered using excel Microsoft software. Data from each locality were entered in different excel sheet and then verified for accuracy. Then these data were fused in one excel sheet to have one entire database. $30 \%$ of the data were re-entered and compared to the initial data to verify any errors. The percentage weightfor-age (\%W/A) index was calculated for each child using his age and weight and the NCHS/WHO references in order to determine the nutritional status of the child. The final database was then cleaned and a code was attributed to each data after which the data were transferred to SPSS version 16.0 for statistical analysis.

The data obtained were expressed as percentages (prevalence and frequency) for qualitative analysis. Differences between the parameters of boys and girls were studied using analysis of variance (ANOVA) since the variables had a normal distribution. The chi-square test was used to check for associations between the dependent variable and the independent variables. Differences between various groups were considered as significant when the $\mathrm{p}$ value was less than 0.05 .

\section{Ethical Consideration}

This study was approved by the National Ethic Committee of Research for Human Health of Cameroon ( $\mathrm{N}^{\circ}$ 2014/04/447/CE/ CNERSH/SP). Oral consent was also given by the heads of each district hospital. The parent or the care giver of each child gave his/her written consent after the objectives, the minimal risk and benefits of the study were well explained. To ensure the confidentiality of the collected data, codes were attributed to each child and no name was revealed.

\section{Dissemination and utilization of results}

The results of the study were presented to the Department of Biology of the Higher Teacher's Training College of the University of Bamenda as part of the requirement for the Diploma of Grade II Teacher in Biology. The results were also presented to the parents of the children who participated in the study so as to inform them on their children's state so that major actions could be taken if their children were malnourished. Also these results will be made available to the Delegation of public health of the North West region. Effort will also be made to present these results at conferences and publish them in peer review journals.

\section{Results}

\section{Demographics and socio-economic characteristics}

Only a few $(23.8 \%)$ of the children in the study population were sick and the majority (76.2\%) of the other children were in good health. Most (43.3\%) of the fathers had a secondary educational level, compared to $13.0 \%$ who had undergone higher education. Most of the mothers $(73.9 \%)$ in the study population did odd jobs, $17.6 \%$ were house wives and $8.5 \%$ were civil servants. The majority $(59.1 \%)$ of the parents (mother and father) did odd jobs; $15.4 \%$ of the children had a parent who did an odd job \& another who was a civil servant; $12.9 \%$ of them had a combination of odd job and unemployed; $6.5 \%$ had the combination, civil servant and unemployed and $6.2 \%$ had the combination of both parents being civil servants. $43.3 \%$ of the Children had fathers with a secondary educational level, $37.0 \%$ had fathers with a primary education, $13.0 \%$ had fathers with a tertiary education 
Citation: Laure NJ, Christelle MM, Bilkha L, Desire MH, Julius O (2014) Nutritional Status and Risk Factors of Malnutrition among 0-24 Months Old Children Living in Mezam Division, North West Region, Cameroon. J Nutr Disorders Ther 4: 150. doi:10.4172/2161- 0509.1000150

Page 4 of 10

\begin{tabular}{|c|c|c|c|}
\hline Characteristics & & Frequency & Percent \\
\hline \multirow{6}{*}{ children age } & $0-3$ months & 120 & 12.12 \\
\hline & 3-6 months & 327 & 33.03 \\
\hline & 6-9 months & 255 & 25.76 \\
\hline & 9-12 months & 129 & 13.03 \\
\hline & $12-18$ months & 96 & 9.7 \\
\hline & $18-24$ months & 63 & 6.36 \\
\hline \multirow{3}{*}{ Mother's age } & $16-25$ years & 162 & 16.36 \\
\hline & 26-35years & 696 & 70.3 \\
\hline & $36-45$ years & 132 & 13.33 \\
\hline \multirow{4}{*}{ Type of illness } & malaria+anemia & 51 & 21.25 \\
\hline & diarrhea+worms & 30 & 12.5 \\
\hline & respiratory diseases & 84 & 35 \\
\hline & malnutrition & 75 & 31.25 \\
\hline \multirow{2}{*}{ Morbidity } & yes & 231 & 23.77 \\
\hline & no & 741 & 76.23 \\
\hline Vacinnation & Yes & 981 & 100,00 \\
\hline \multirow{2}{*}{ Infant feeding } & Exclusive breast feeding & 630 & 64,22 \\
\hline & mixed & 351 & 35,78 \\
\hline \multirow{3}{*}{ Marital status } & married & 657 & 66,97 \\
\hline & single & 312 & 31,80 \\
\hline & widow & 12 & 1,22 \\
\hline \multirow{4}{*}{ Family occupation } & Odd job+civil servant & 150 & 15,15 \\
\hline & odd jobs \& odd jobs & 576 & 59,08 \\
\hline & Father \& Mother civil servant & 60 & 6,15 \\
\hline & Civil servant + un employed & 63 & 6,46 \\
\hline \multirow[b]{2}{*}{ Occupation of father } & odd jobs & 732 & 75,08 \\
\hline & Civils servants & 243 & 24,90 \\
\hline \multirow{3}{*}{ Occupation of mother } & house wife & 174 & 17,63 \\
\hline & odd jobs & 729 & 73,86 \\
\hline & civil servants & 84 & 8,51 \\
\hline \multirow{3}{*}{$\begin{array}{c}\text { Mother's educational } \\
\text { level }\end{array}$} & primary school & 423 & 42,73 \\
\hline & Secondary & 513 & 51,82 \\
\hline & University & 48 & 4,85 \\
\hline \multirow{3}{*}{$\begin{array}{c}\text { Father's educational } \\
\text { level }\end{array}$} & primary school & 366 & 36,97 \\
\hline & Secondary & 429 & 43,33 \\
\hline & University & 129 & 13,03 \\
\hline \multirow{2}{*}{ Sex } & girls & 429 & 43,33 \\
\hline & boys & 561 & 56,67 \\
\hline
\end{tabular}

Table1: Demographics and socio-economic characteristics.

(university level) and 2.3\% had illiterate fathers. Most children $51.8 \%$ had mothers with a secondary educational level, $42.7 \%$ of them had mothers with a primary educational level, $4.9 \%$ had mothers with tertiary education (university level) and $3 \%$ of them had illiterate mothers.

\section{Comparative studies between NCHS references and the study population}

The growth curve of the study population was an undulating one; the children experienced an irregular growth pattern compared with the NCHS reference growth curve. From the age of 2 months to 6 months, the female children were slightly overweight; weighing $5.5 \mathrm{~kg}$ instead of $4.7 \mathrm{~kg}$ at 2 months and at 6 months, they weighed $7.7 \mathrm{~kg}$ instead of $7.2 \mathrm{~kg}$, at 7 months, there was a drop; their weight was $7.3 \mathrm{~kg}$ instead of $7.7 \mathrm{~kg}$; this was maintained until the age of 9 months, when they weighed $8.2 \mathrm{~kg}$ instead of $8.4 \mathrm{~kg}$; at $10 \mathrm{months}$, they were slightly overweight, weighing $9.2 \mathrm{~kg}$ instead of $8.9 \mathrm{~kg}$. At 11 months, they experienced a drastic drop in their weights, weighing $8.3 \mathrm{~kg}$ instead of $9.2 \mathrm{~kg}$ up to the age of 13 months where they weighed $9.1 \mathrm{~kg}$ instead of $9.8 \mathrm{~kg}$. At 14 months, they experienced another increase in weight, weighing $10.6 \mathrm{~kg}$ instead of
$10 \mathrm{~kg}$. From the age of 18 months, they experienced another drop in their weight until the age of 24 months.

The female population under study experienced an irregular growth pattern but obvious drops at 11 months and 18 months were probably due to the fact that the mothers of these children did not follow appropriate infant feeding practices. At the age of 2-6 months the mothers did not exclusively breastfeed their children accounting for the fact that children of this age group weighed more than the reference. In the case where the female children weighed less than the reference population for example from 11-18 months, age at which appropriate complementary foods in addition to breast milk are needed by these children might be because these type of foods were not provided to these children. Feeding practices as pointed out by Harder and collaborators in 2005 [30], during infancy are important for growth and development, and might affect eating habits later in childhood (Figure $1)$.

The growth curve of the boys in the study population was almost identical to that of the NCHS reference growth curve until the age of 22 months where, instead of weighing $12.2 \mathrm{~kg}$ they weighed $14 \mathrm{~kg}$ and then became normal again at 24 months (Figure 2).

This could be as a result of the type of complementary food given to children of that age. Over consumption of energy-dense complementary foods may induce excessive weight gain in infancy, which has been associated with a 2 to 3 -fold higher risk of obesity in childhood [29].

\section{Factors associated with malnutrition in the study population}

Prevalence of Malnutrition in girls with respect to age range: $50 \%$ of the female children in the range 0-3 months were undernourished (moderate malnutrition). In the range 3-6months there were 42.7\% undernourished children (severe, moderate, mild cases of

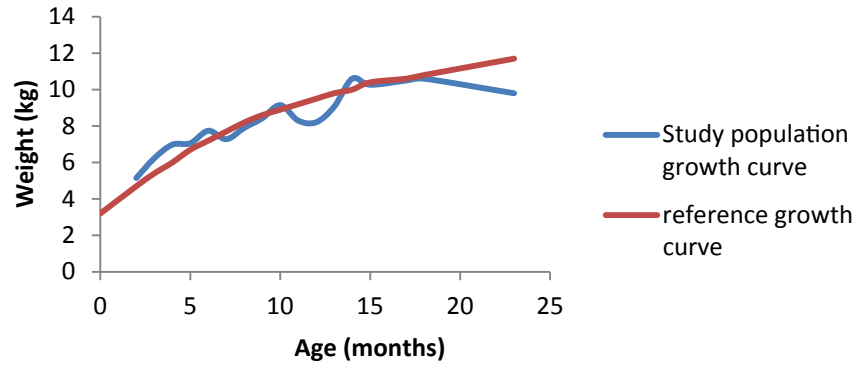

Figure 1: Comparative study between NCHS references and the population of girls.

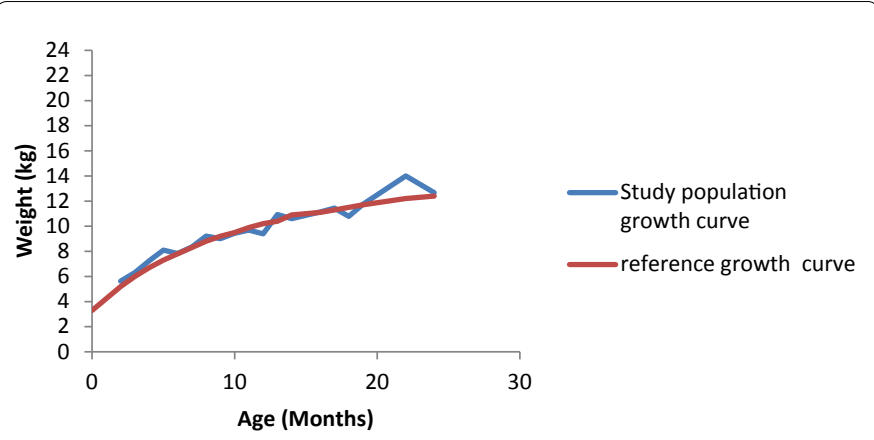

Figure 2: Comparative study between NCHS references and the population of boys. 
Citation: Laure NJ, Christelle MM, Bilkha L, Desire MH, Julius O (2014) Nutritional Status and Risk Factors of Malnutrition among 0-24 Months Old Children Living in Mezam Division, North West Region, Cameroon. J Nutr Disorders Ther 4: 150. doi:10.4172/2161- 0509.1000150

Page 5 of 10

\begin{tabular}{|c|c|c|c|}
\hline Age (months) & Nutritional status & Frequency & Percent \\
\hline \multirow{4}{*}{$0-3$} & Moderately Underweight & 6 & 50 \\
\hline & normal weight & 3 & 25 \\
\hline & overweight & 3 & 25 \\
\hline & Total & 12 & 100 \\
\hline \multirow{6}{*}{ 6-Mar } & Severely Underweight & 3 & 1.64 \\
\hline & Moderately Underweight & 27 & 14.75 \\
\hline & Mildly Underweight & 48 & 26.23 \\
\hline & normal weight & 72 & 39.34 \\
\hline & overweight & 33 & 18.03 \\
\hline & Total & 183 & 100 \\
\hline \multirow{5}{*}{ 9-Jun } & Moderately Underweight & 18 & 15.79 \\
\hline & Mildly Underweight & 12 & 10.53 \\
\hline & normal weight & 33 & 28.95 \\
\hline & overweight & 51 & 44.74 \\
\hline & Total & 114 & 100 \\
\hline \multirow{5}{*}{ 12-Sep } & Moderately Underweight & 3 & 5.56 \\
\hline & Mildly Underweight & 9 & 16.67 \\
\hline & normal weight & 21 & 38.89 \\
\hline & overweight & 21 & 38.89 \\
\hline & Total & 54 & 100 \\
\hline \multirow{4}{*}{ 18-Dec } & Mildly Underweight & 9 & 20 \\
\hline & normal weight & 6 & 13.33 \\
\hline & overweight & 30 & 66.67 \\
\hline & Total & 45 & 100 \\
\hline \multirow{3}{*}{$18-24$} & normal weight & 9 & 42.86 \\
\hline & overweight & 12 & 57.14 \\
\hline & Total & 21 & 100 \\
\hline
\end{tabular}

Table 2: Prevalence of under- and overnutrition in girls with respect to Age range.

undernutrition). In the range 6-9 months, $26.3 \%$ were undernourished (moderate and mild cases of undernutrition). $22.3 \%$ of those in the range 9-12 months were undernourished (moderate and mild cases of undernutrition). $20 \%$ of those in the range $12-18$ months were undernourished (mild case undernutrition). This age group recorded the highest prevalence of overnutrition $(66.7 \%)$. In the range 18-24 months, there was no case of undernourished children but it recorded $57.1 \%$ overweight children (Table 2 ).

The trend of malnutrition in the age ranges was as follows: 0-3 months were the most undernourished, followed by the 3-6 months age group which were inturn more under nourished than the 6-9 months old children who were also more undernourished than children in the 9-12 months age group, followed by the 12-18 months age group and lastly, the 18-24 months age group which had no case of undernourished children.

Prevalence of Malnutrition with respect to sex: The level of undernutrtion was higher in girls (31.5\%) (with cases of severe, moderate and mild malnutrtion) than in boys (30.6\%) who also had cases of severe, moderate and mild malnutrition.Therefore, girls were more undernourished than boys. There was a high prevalence of overnutrition amongst boys than girls (Figure 3). Generally, girls are more moody than boys and could at times refuse to be fed, reason why they have high chances of being more undernourished than boys. This could also be explained by the fact that, in terms of appetite, boys have a huge appetite compared to girls.

Prevalence of Malnutrition in boys with respect to age range: $63.9 \%$ of the male children in the range $0-3$ months were undernourished (cases of severe, moderate, mild under nutrition). Those in the range 3-6months had $37.5 \%$ undernourished children (cases of severe, moderate, mild under nutrition). In the range 6-9 months, $19.1 \%$ were undernourished ( 1 case of mild undernutrition). $20 \%$ of those in the range 9-12 months were undernourished (cases of moderate and mild undernutrition). $5.8 \%$ of those in the range 12 18 months were undernourished ( 1 case of mild undernutrition) and recorded the highest prevalence of overweight (82.4\%). In the range 1824 months, there was no case of undernourished children but recored $71.4 \%$ over weights (Table 3 ).

Therefore the trend in under nutrition was as follows: children in the $0-3$ months age group were more undernourished than those in the 3-6 months age group, who were more undernourished than those in the 9-12 months age group who in turn were more undernourished than the 6-9 months male children who were more under nourished

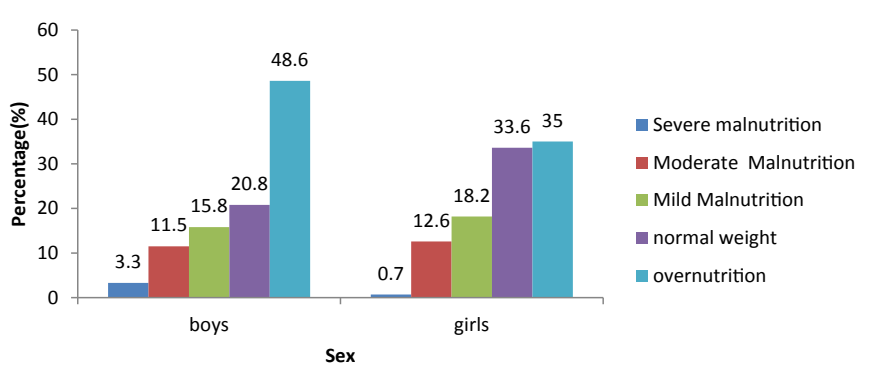

Figure 3: Prevalence of under- and overnutrition with respect to sex.

\begin{tabular}{|c|c|c|c|}
\hline Age (Months) & Nutritional status & Frequency & Percent \\
\hline \multirow{6}{*}{$0-3$} & Severely Underweight & 15 & 13.89 \\
\hline & Moderate Underweight & 39 & 36.11 \\
\hline & Mildly Underweight & 15 & 13.89 \\
\hline & normal weight & 21 & 19.44 \\
\hline & Overweight & 18 & 16.67 \\
\hline & Total & 108 & 100 \\
\hline \multirow{6}{*}{ 6-Mar } & Severe Underweight & 3 & 2.08 \\
\hline & Moderate Underweight & 21 & 14.58 \\
\hline & Mildly Underweight & 30 & 20.83 \\
\hline & normal weight & 33 & 22.92 \\
\hline & Overweight & 57 & 39.58 \\
\hline & Total & 144 & 100 \\
\hline \multirow{4}{*}{ 9-Jun } & Mildly Underweight & 27 & 19.15 \\
\hline & normal weight & 39 & 27.66 \\
\hline & Overweight & 75 & 53.19 \\
\hline & Total & 141 & 100 \\
\hline \multirow{5}{*}{ 12-Sep } & Moderate Underweight & 3 & 4 \\
\hline & Mildly Underweight & 12 & 16 \\
\hline & normal weight & 15 & 20 \\
\hline & Overweight & 45 & 60 \\
\hline & Total & 75 & 100 \\
\hline \multirow{4}{*}{ 18-Dec } & Mildly Underweight & 3 & 5.88 \\
\hline & normal weight & 6 & 11.76 \\
\hline & Overweight & 42 & 82.35 \\
\hline & Total & 51 & 100 \\
\hline 18-Dec & Overweight & 42 & 100 \\
\hline
\end{tabular}

Table 3: Prevalence of under- and overnutrition in boys with respect to age range. 


\begin{tabular}{|c|c|c|c|c|}
\hline $\begin{array}{l}\text { Kind of milk } \\
\text { feeding }\end{array}$ & Sex & Nutritional status & Frequency & Percent \\
\hline \multirow{11}{*}{$\begin{array}{l}\text { Exclusive breast } \\
\text { feeding }\end{array}$} & \multirow{5}{*}{ girls } & Moderately Underweight & 33 & 14.28 \\
\hline & & Mild Underweight & 51 & 22 \\
\hline & & normal weight & 78 & 33.76 \\
\hline & & Overweight & 69 & 29.87 \\
\hline & & Total & 231 & 100 \\
\hline & \multirow{6}{*}{ boys } & Severely Underweight & 15 & 3.84 \\
\hline & & Moderately Underweight & 54 & 13.84 \\
\hline & & Mild Underweight & 57 & 14.61 \\
\hline & & normal weight & 72 & 18.46 \\
\hline & & Overweight & 192 & 49.23 \\
\hline & & Total & 390 & 100 \\
\hline \multirow{12}{*}{ Mixed } & \multirow{6}{*}{ girls } & Severely Underweight & 3 & 1.53 \\
\hline & & Moderately Underweight & 21 & 10.76 \\
\hline & & Mild Underweight & 27 & 13.84 \\
\hline & & Normal weight & 66 & 33.84 \\
\hline & & Overweight & 78 & 40 \\
\hline & & Total & 195 & 100 \\
\hline & \multirow{6}{*}{ boys } & Severely Underweight & 3 & 1.96 \\
\hline & & Moderately Underweight & 9 & 5.88 \\
\hline & & Mild Underweight & 27 & 17.64 \\
\hline & & normal weight & 42 & 27.45 \\
\hline & & Overweight & 72 & 47.05 \\
\hline & & Total & 156 & 100 \\
\hline
\end{tabular}

Table 4: Prevalence of under- and over nutrition in girls and boys with respect to the kinds of milk feeding.

than the 12-18 months aged children and then the 18-24 months age group who had no cases of undernourishment. These results did not tie with the local and regional studies in Ethiopia which have shown an increase in under nutrition with increase in age of the child [16]. This might be because the older children received complementary foods of good nutritional quality than the younger ones accounting for the fact that most older children had a better nutritional status than the younger ones. Also the younger children could have been affected by a morbid state. Amongst the boys, the 9-12 months children were more undernourished than the 6-9 months age group which is line with the observation made above by Yimer in 2000 [16]. The fact that the 18-24 months age group female children were found with a high prevalence of overnutrition could be because these children in addition to receiving complementary foods of good nutritional quality, they equally received these foods in great quantity.

Prevalence of Malnutrition with respect to kinds of milk feeding: In exclusively breast fed girls, $36.4 \%$ of the children were undernourished (mild and moderate cases) and 29.9\% of them over nourished. On the other hand, in mixed fed infants, 33.3\% of the children were undernourished (severe, moderate and mild cases) and $40 \%$ of them over nourished (Table 4 ). Therefore female children who were exclusively breast fed were more undernourished than those who were mixed fed and the later were more over nourished than those who were exclusively fed. This could be explained by the fact that the children who were exclusively breast fed were not introduced to complementary feeding at the appropriate time.

The fact that most mixed fed female children were overweight than exclusively breast fed female children might be because the former tend to ingest greater volume of artificial milk or food and since the concentration of some nutrients are greater in infant formula than in breast milk [17], these children may tend to gain weight.

These results are different from the study carried out in Malawi on breast feeding and mixed feeding practices which revealed that early introduction of food with limited nutritional values, was related to poor growth in the Malawi population [18]. The children of the study population could have been introduced to food with high nutritional values.

Boys who had been exclusively breastfed recorded the highest levels of severely underweights (3.84\%) and moderately underweights (13.84\%). This group also recorded the highest levels of over nutrition (49.2\%). While boys who had received mixed feeding recorded the highest level of mildly underweight children (Table 4).

Children who were exclusively breastfed were more undernourished than those who were mixed fed. This could be as a result of extensive breast feeding pass 6 months; given that after 6 months, children need more nutrients which cannot be provided by breast milk alone. These results were different from those obtained in a study carried out in Botswana on the factors affecting the prevalence of malnutrition among children under three years of age in Botswana by Salah et al. [19], where the prevalence of underweights among children who were breastfed occurred to a substantially lower level than among children who were never breastfed.

Prevalence of Malnutrition in girls with respect to mother's educational level: All the children (100\%) with illiterate mothers, $32.9 \%$ of the children with mothers who had just a primary education and $33.3 \%$ of children whose mothers had just a tertiary education were undernourished. A lower prevalence of malnutrition was noticed in the group of children (28\%) with mothers who had just a secondary education.

Therefore the trend in malnutrition was as follows: illiterate mothers had children who were the most undernourished followed by tertiary educated mothers (university) who had more undernourished children than primary educated mothers who also had more undernourished children than secondary educated mothers and the latter had the highest prevalence of over nourished children (37.3\%) (Figure 4).

All the children of illiterate mothers were underweight; the next on the list were the children of those of the university level. Although we were expecting that those children from parents at the university level were going to be the best well-nourished, the children of illiterate mothers nevertheless were the most undernourished, meaning that education of the mothers had little or no role to play in the nutritional status of these children; it could be probable that the mothers at the

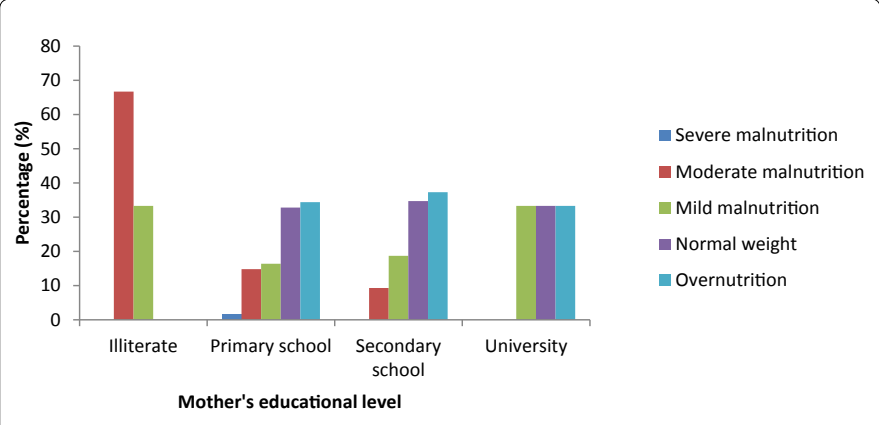

Figure 4: Prevalence of under- and overnutrition in girls with respect to mother's educational level. 


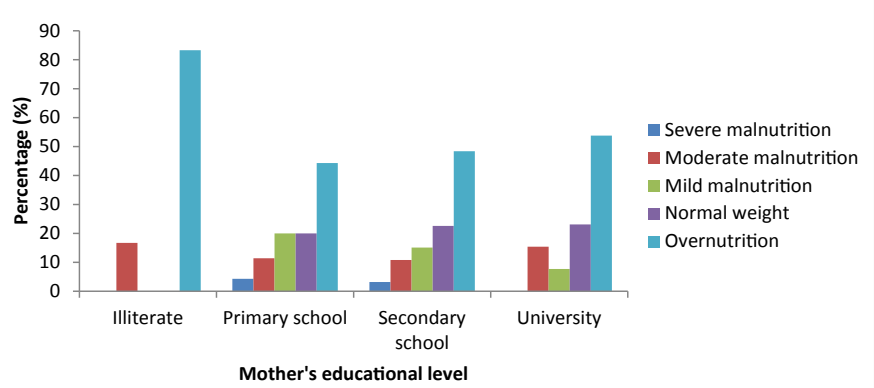

Figure 5: Prevalence of under- and overnutrition in boys with respect to mother's educational level.

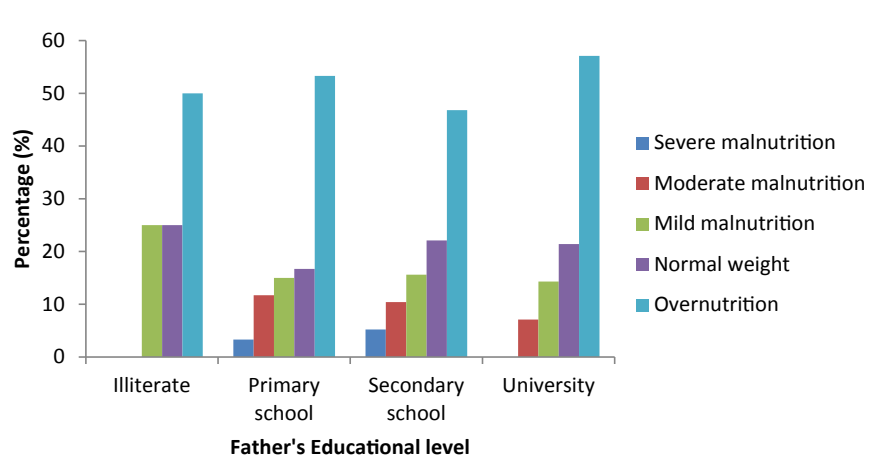

Figure 6: Prevalence of under- and overnutrition in boys with respect to father's educational level.

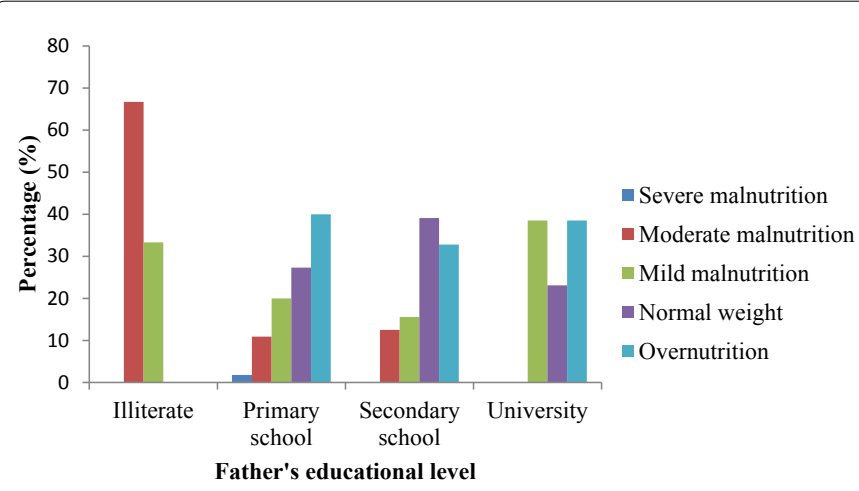

Figure 7: Prevalence of under- and overnutrition in girls with respect to father's educational level.

tertiary level of education were so busy and didn't devote time to care for their children. These results did not tie with the results obtained in a study in Botswana on the nutritional status of children 0-3 years in which there were significant differences $(p<0.01)$ between each two consecutive levels of education $(29.4 \%$ for no education; $18.3 \%$ for primary education, $12.9 \%$ for secondary education and $0.0 \%$ for tertiary education) [20]. The results also differed from studies in Libya [21], Uganda [22], and Ethiopia [23] which observed a decreased incidence of malnutrition among young children with an increase in the level of mother's education.

Prevalence of malnutrition in boys with respect to mother's educational level: $16.7 \%$ of male children with illiterate mothers were undernourished and $83.3 \%$ of them were over nourished. $35.7 \%$ of the male children with mothers who had just a primary education were undernourished. $29.1 \%$ of the children with mothers who had just a secondary education were undernourished whereas $23.1 \%$ of the children whose mothers had just a tertiary education were undernourished.

Therefore the trend in under nutrition was as follows: Mothers with a primary education had children who were the most undernourished; followed by those who had secondary education, then mothers who had been to the university and lastly illiterate mothers who had the highest prevalence of over nourished male children (Figure 5). This could be explained by the fact that illiterate mothers don't go to school and thus have time to take care of their children. These results were contrary to studies in Libya [21], Uganda [22], and Ethiopia [23] which showed a decreased incidence of malnutrition among young children with an increase in the level of mother's education.

Prevalence of malnutrition in boys with respect to father's educational level: $25 \%$ of children with illiterate fathers were undernourished (mild case of malnutrition). 30\% of children with fathers who had just a primary education were undernourished (Severe, moderate and mild cases). $31.2 \%$ of children whose fathers had just a secondary education were undernourished (severe, moderate, mild cases). $1.4 \%$ of children whose fathers had just a tertiary education were undernourished (mild and moderate cases). Therefore the trend in under nutrition was as follows: Fathers with a secondary educational level had children who were the most undernourished; followed by those who had primary education, who in turn were more undernourished than children with illiterate fathers, and lastly the children of fathers with a university level. This group of fathers had the highest prevalence of over nourished children (Figure 6). This can be explained by the fact that fathers with a university level later have jobs which generate high income which tend to increase the level of household income and enable the parents of these homes to get access to high nutritious foods for these children.

Prevalence of malnutrition in girls with respect to father's educational level: $100 \%$ of the children whose fathers were illiterates were malnourished (moderate and mild malnutrition), 32.7\% of children whose fathers had a primary educational level were undernourished (severe, moderate and mild). $28.1 \%$ of female children with fathers who had undergone secondary education were undernourished (mild and moderate cases). $38.5 \%$ of children whose fathers had undergone tertiary education were undernourished (mild cases).

The trend in malnutrition was as follows: Fathers who were illiterates, had the most undernourished children, followed by those who had been to the university, then those who went just through primary education, who also had the highest prevalence of over nutrition (40\%) and lastly, those who went just through secondary education (Figure 7). Just like mothers, the educational level of fathers influence the nutritional status of the child. It is obvious that the children from illiterate fathers should be undernourished but the normal expected trend is upset, given that the next undernourished children are those from tertiary educated fathers. These results were contrary to studies in the Philippines, Libya (21), Uganda (22), and Ethiopia (16, 23).

Prevalence of malnutrition in girls with respect to mother's marital status: Among married women, $32.4 \%$ of the children were undernourished (severe, moderate and mild cases). Among the single ones, $28.1 \%$ of the children were undernourished (severe, moderate and mild cases). This group had the highest prevalence of over nourished children. Among the widows, $25 \%$ of the children were undernourished 


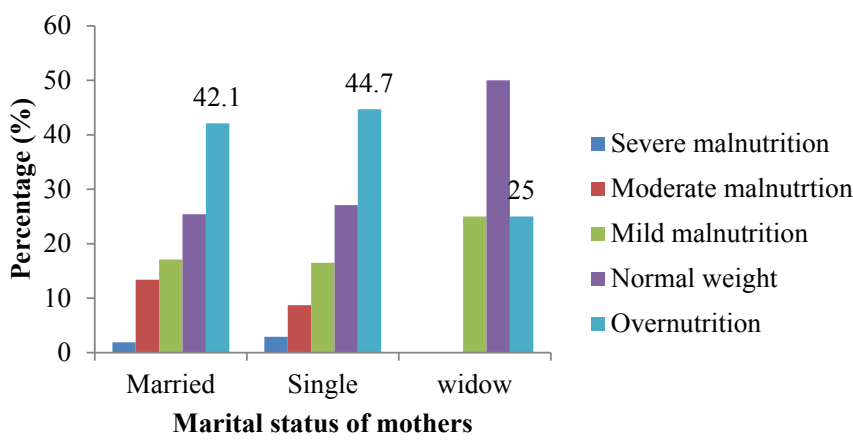

Figure 8: Prevalence of under- and overnutrition in the study population with respect to mother's marital status.

\begin{tabular}{|c|c|c|c|c|}
\hline Sex & Age & Nutritional Status & Frequency & Percent \\
\hline \multirow{16}{*}{ Girls } & $15-24$ years & Severely Underweight & 3 & 3.57 \\
\hline & & Moderately Underweight & 3 & 3.57 \\
\hline & & Mildly Underweight & 12 & 14.28 \\
\hline & & normal weight & 36 & 42.85 \\
\hline & & overweight & 30 & 35.71 \\
\hline & & Total & 84 & 100 \\
\hline & 25-34years & Moderately Underweight & 39 & 13.26 \\
\hline & & Mildly Underweight & 57 & 19.38 \\
\hline & & normal weight & 93 & 31.63 \\
\hline & & overweight & 105 & 35.71 \\
\hline & & Total & 294 & 100 \\
\hline & $35-44$ years & Moderately Underweight & 12 & 23.52 \\
\hline & & Mildly Underweight & 9 & 17.64 \\
\hline & & normal weight & 15 & 29.41 \\
\hline & & overweight & 15 & 29.41 \\
\hline & & Total & 51 & 100 \\
\hline \multirow{12}{*}{ Boys } & $15-25$ yeras & Severely malnutrition & 3 & 3.84 \\
\hline & & Moderately Underweight & 18 & 23.07 \\
\hline & & Mildly Underweight & 9 & 11.53 \\
\hline & & normal weight & 12 & 15.38 \\
\hline & & overweight & 36 & 46.15 \\
\hline & & Total & 78 & 100 \\
\hline & $25-35$ years & Severely malnutrition & 15 & 3.84 \\
\hline & & Moderately Malnutrition & 39 & 10 \\
\hline & & Mildly Malnutrition & 69 & 17.69 \\
\hline & & normal weight & 81 & 20.76 \\
\hline & & overweight & 186 & 47.69 \\
\hline & & Total & 390 & 100 \\
\hline
\end{tabular}

Table 5: Prevalence of under- and overnutrition in the study population with respect to mother's age.

(mild case). Therefore, children born of married women were the most malnourished followed by those from single women and lastly, widows (Figure 8).

This, probably because married women devote more time to family issues and less time is devoted to take care of the child. Although the actual amount of food ingested by a child is closely related to food security, it is critically dependent on the care - related feeding behaviours of the child's caretaker, such as breast feeding, complementary feeding and food preparation [24]. Six categories of care are recognised: care of women, young child feeding practices, psychosocial care, and preparation of meals, hygiene behaviour, and health behaviour [25]. Single mothers probably, give in more time to care for their babies. These results were not in line with a study carried out in the Southern Nations, Nationalities and Peoples Region of Ethiopia [16], which showed that children's nutrition is significantly associated with marital status indicating that compared to married women, malnutrition is higher among unmarried rural and divorced (separated) urban women compared to married ones. The prevalence of malnutrition was highest among never-married women (36\%), followed by widowed (32\%) and divorced women (29\%).

Prevalence of malnutrition in the study population with respect to parents' revenue: $25 \%$ of the Children who had one parent who did an odd job and another who was a civil servant were undernourished (severe, moderate and mild cases). For the case where both parents did odd jobs, $31.5 \%$ of the children were undernourished (severe, moderate, mild cases). For the case where both parents were civil servants, $35 \%$ of the children were undernourished (mild and moderate cases). For the case where one parent was a civil servant and the other unemployed, $35 \%$ of the children were undernourished (mild and moderate cases). For the case where one parent did an odd job and the other unemployed, $33.4 \%$ of the children were undernourished (mild and moderate cases).

Therefore, children who had parents who were both civil servants and those who had one parent being a civil servant and the other unemployed were the most undernourished followed by children with both parents doing odd jobs and lastly, children with one parent doing an odd job and the other a civil servant. The highest prevalence of over nutrition (55\%) was observed among children who had one parent as civil servant and the other unemployed ( ).

The reason could probably be because those who are civil servants, though they have enough income to raise their children, devote little or no time to child care. In the case of one parent doing an odd job and the other being a civil servant, the children had the lowest percentage of being undernourished. This might surely be because those who did odd jobs, created time for their babies. The results obtained did not tie with results obtained from pass research: comparative studies on child nutrition for more than 15 countries [26] and some local studies in Ethiopia [16,23] showed that the higher the level of economic status of a household, the lower the level of under nutrition.

Prevalence of under- and overnutrition in the study population with respect to mother's age: In both girls and boys, mothers aged 15-25 years were the only ones with severely malnourished children

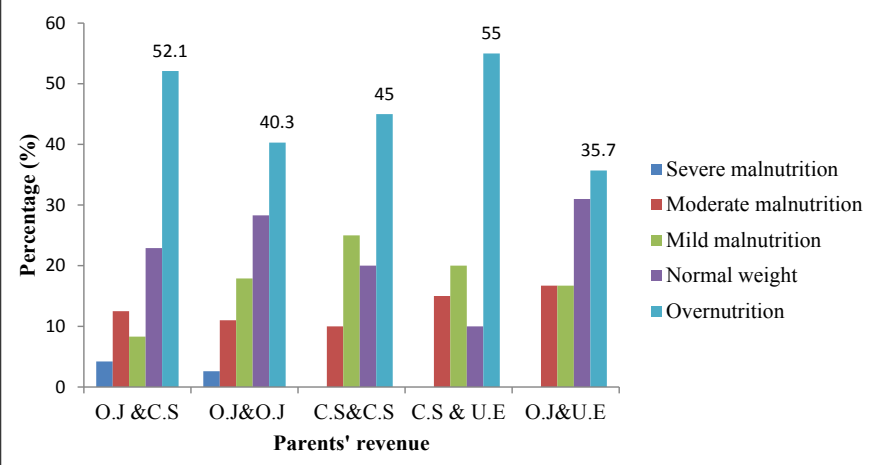

O.J= Odd jobs, C.S=Civil servant, U.E=Unemployed.

Figure 9: Prevalence of under- and overnutrition in the study population with respect to parent's revenue. 
Citation: Laure NJ, Christelle MM, Bilkha L, Desire MH, Julius O (2014) Nutritional Status and Risk Factors of Malnutrition among 0-24 Months Old Children Living in Mezam Division, North West Region, Cameroon. J Nutr Disorders Ther 4: 150. doi:10.4172/2161- 0509.1000150

Page 9 of 10

\begin{tabular}{|c|c|c|c|c|}
\hline Sex & Age & Nutritional Status & Frequency & Percent \\
\hline \multirow{16}{*}{ Girls } & $15-24$ years & Severely Underweight & 3 & 3.57 \\
\hline & & Moderately Underweight & 3 & 3.57 \\
\hline & & Mildly Underweight & 12 & 14.28 \\
\hline & & normal weight & 36 & 42.85 \\
\hline & & overweight & 30 & 35.71 \\
\hline & & Total & 84 & 100 \\
\hline & 25-34years & Moderately Underweight & 39 & 13.26 \\
\hline & & Mildly Underweight & 57 & 19.38 \\
\hline & & normal weight & 93 & 31.63 \\
\hline & & overweight & 105 & 35.71 \\
\hline & & Total & 294 & 100 \\
\hline & $35-44$ years & Moderately Underweight & 12 & 23.52 \\
\hline & & Mildly Underweight & 9 & 17.64 \\
\hline & & normal weight & 15 & 29.41 \\
\hline & & overweight & 15 & 29.41 \\
\hline & & Total & 51 & 100 \\
\hline \multirow{12}{*}{ Boys } & $15-25$ yeras & Severely malnutrition & 3 & 3.84 \\
\hline & & Moderately Underweight & 18 & 23.07 \\
\hline & & Mildly Underweight & 9 & 11.53 \\
\hline & & normal weight & 12 & 15.38 \\
\hline & & overweight & 36 & 46.15 \\
\hline & & Total & 78 & 100 \\
\hline & $25-35$ years & Severely malnutrition & 15 & 3.84 \\
\hline & & Moderately Malnutrition & 39 & 10 \\
\hline & & Mildly Malnutrition & 69 & 17.69 \\
\hline & & normal weight & 81 & 20.76 \\
\hline & & overweight & 186 & 47.69 \\
\hline & & Total & 390 & 100 \\
\hline
\end{tabular}

Table 5: Prevalence of under- and overnutrition in the study population with respect to mother's age.

(3.6\% of girls and $3.9 \%$ of boys). In girls, moderately malnourished children $(23.5 \%)$ were mostly found with mothers in the $35-44$ years age group while for boys these children (23.1\%) were mostly found with mothers within the 15-25 years age group. Overweight female children were mostly found among mothers within the 15-25 and 2534 years age groups which were respectively $35.71 \%$. Whereas for male children, over weights (47.7\%) were mostly found among mothers in the 25-34 years age group (table 5).In this study, mother's age affects the nutritional status of her child. The fact that severely malnourished children were found among mothers in the age group 15-25 years can be explain by the fact that, these mothers being still very young, lack the maturity and nutritional knowledge to take care of their children.

Also, it has been pointed out that, in many countries young mothers in the age group 15-19 years are the ones mostly suffering from chronic energy deficiency [28]. These young mothers being malnourished themselves might account for the fact that their children too are malnourished. The fact that overweight children were mostly found among mothers in the 25-34 years age group might be explained by the fact that these mothers being young and active tend to feed their children a lot or to leave their children in the hands of their house helps when they go to work or school. The latter tend not to practice appropriate child feeding practices.

\section{Limitation of study}

We hope to throw more light on this work by evaluating the nutritional status of these children, making use of the following anthropometric indices: Weight For Height (WFH) and Height For Age (HFA).

\section{Conclusions}

The growth patterns of the children of the study were not similar to those of the NCHS/WHO reference population. The prevalence of both under nutrition and over nutrition was high in the Mezam division. There were two extremes in the nutritional status of all the children; for every group and set of children in the study population, be it male or female, there were underweight children and overweight children as well, the prevalence of under nutrition decreased with increased age in both sexes; boys were more over nourished than girls.

Risk factors of under nutrition in these children were as a result of factors such as, nature of parents' profession which gives less time for child care, nature of mother's profession, inappropriate child feeding practices such as exclusive breastfeeding practiced incorrectly and mixed feeding started too early. Risk factors of over nutrition were due to factors such as bottle feeding and early introduction of complementary food (especially energy-dense complementary food) leading to rapid weight gain in infancy.

Although the child welfare clinics housed within the district health offices are doing a great job educating mothers on appropriate nutrition for children, most of the time the fathers are left out, as it is not a cultural practice for fathers to accompany their wives to these clinic sessions. So radio and television could be a means for reaching these fathers through local drama sketches on appropriate child feeding to gain both the interest and support of fathers to ensure children receive optimum nutrition. In summary, attention needs to be given to infant/ child feeding practices, maternal empowerment, and community resources to ensure optimal childhood nutrition. The children are the future of a nation and the entire world. Early inadequate nutrition and the resulting malnutrition have significant negative impact on the future productivity of these individuals and the country as a whole. There is the need to encourage feeding on animal protein and other nutrient dense foods to children (6-24 months) in Mezam division. It is very important for public health interventions, such as nutrition education, appropriate child feeding and care practices, to be taken out of the clinics and placed into the communities and the homes of these underserved audiences for the maximum benefit.

\section{Recommendations}

To reduce childhood malnutrition, emphasis should be made on improving the nutritional practices of parents. Making sure that after a child has received exclusive breast feeding for 6 months, complementary feeding should follow immediately. Men and women should be educated on the importance of frequently taking the weights and heights of their children, as this will help monitor the growth rate of the child hence reducing many nutritional diseases and ill states. This study revealed some of the causes of child malnutrition. One being that, most people are not taught or enlightened on malnutrition in general. The consequences of malnutrition could be avoided or controlled if this topic is also taught in schools.

\section{References}

1. Smith LC and Haddad L (2000) Explaining child malnutrition in developing countries: a cross country analysis. International Food Policy Research Institute, Food Consumption and Nutrition Division discussion paper.

2. UNICEF (2000) Female education. The state of the world children. 
Citation: Laure NJ, Christelle MM, Bilkha L, Desire MH, Julius O (2014) Nutritional Status and Risk Factors of Malnutrition among 0-24 Months Old Children Living in Mezam Division, North West Region, Cameroon. J Nutr Disorders Ther 4: 150. doi:10.4172/2161- 0509.1000150

3. Crawley J (2004) Reducing the burden of anemia in infants and young children in malaria-endemic countries of Africa: from evidence to action. Am J Trop Med Hyg 71: 25-34.

4. Mendez MA, Adair LS (1999) Severity and timing of stunting in the first two years of life affect performance on cognitive tests in late childhood. J Nutr 129: 1555-1562.

5. Keikhaei B, Zandian K, Ghasemi A, Tabibi R (2007) Iron-deficiency anemia among children in southwest Iran. Food Nutr Bull 28: 406-411.

6. Ferrari AA, Solymos GM, Castillo RM, Sigulem DM (1998) Risk factors for protein-energy malnutrition in pre-school shantytown children in São Paulo, Brazil. Sao Paulo Med J 116: 1654-1660.

7. Owor M and Tumwine JK (2000) Risk factors for malnutrition among rural Nigerian children. Asia Pac. J. Clin. Nutr., 15(14): 491-495.

8. Reyes H, Pérez-Cuevas R, Sandoval A, Castillo R, Santos JI, et al. (2004) The family as a determinant of stunting in children living in conditions of extreme poverty: a case-control study. BMC Public Health 4: 57.

9. Vella V, Tomkins A, Nidku J, Marshall T (1992) Determinants of child mortality in south-west Uganda. J Biosoc Sci 24: 103-112.

10. Kengne Nouemsi AP , Ngondi Judith L and Oben Julius Enyong (2007) Factors Associated with Breast feeding as Well as the Nutritional Status of Infants (012) Months. Pakistan Journal of Nutrition 6 (3): 259-263.

11. UNICEF CAMEROON (2009). Silent Emergency Affecting children in Cameroon. UNICEF humanitarian action update. Cameroon, March 2009.

12. Wagstaff $A$ and Watanabe $N(2000)$ socioeconomic inequalities in child $m$ alnutrition in the developing world. Policy Research Working Paper 2434, World Bank.

13. Hong R (2007) Effect of economic inequality on chronic childhood undernutrition in Ghana. Public Health Nutr 10: 371-378.

14. Chavez r, Frenk s, Galvan rr, Gomez f, Munoz jc, et al. (1956) mortality in second and third degree malnutrition. $\mathrm{J}$ trop pediatr (lond) 2: 77-83.

15. Samson T and Lakech G (2000) Malnutrition and enteric parasites among under five children in Aynalem village, Tigray. Ethiopian Journal of Health Development 14: 67-75.

16. Yimer G (2000) Malnutrition among children in southern Ethiopia: Levels and risk factors. Ethiopian Journal of Health Development 14:283-292.

17. Agostoni C, Decsi T, Fewtrell M, Goulet O, Kolacek S, et al. (2008) Complementary feeding: a commentary by the ESPGHAN Committee on Nutrition. J Pediatr Gastroenterol Nutr 46: 99-110.

18. Kerr RB, Berti PR, Chirwa M (2007) Breastfeeding and mixed feeding practices in Malawi: timing, reasons, decision makers, and child health consequences. Food Nutr Bull 28: 90-99.

19. Salah EO Mahgoub, Maria Nnyepi, Theodore Bandeke (2006) Factors Affecting Prevalence of Malnutrition among Children under Three years of Age in Botswana. African Journal of food Agriculture and Nutritional Development (AJFAND): Volume 6 No. 12006.
20. Ubombo-Jaswa S and Belbase K (1996) Determinants of child nutritional status in Botswana: A national study. (Gaborone, Botswana), Food Strategy unit Rural development coordination Division, Ministry of Finance and development planning; Food and Nutrition Unit, Family Health Division, Ministry of Health; and UNICEF, Botswana.

21. Popkin BM, and Bisgrove EZ (1988) Urbanization and nutrition in low income countries. Food and Nutrition Bulletin 10:3-4

22. Statistics Department Uganda and Macro International Inc (1996) Uganda Demographic and Health Survey. 1995. Calverton, Maryland, USA: Macro International Inc

23. Genebo T, Girma W, Hadir J, and Demmissie T (1999). The association of childrens nutritional status to maternal education in Ziggbaboto, Guragie Zone South Ethiopian Journal of Health Development 13:55-61.

24. WHO (1999) Management of severe malnutrition: a manual for physicians and other senior health works. Geneva, WHO.

25. Ouedraogo H Z, Nikiema L, Some I, Sakande J, Dramaix-wilme and P Donnen (2008) Home-Based Practices of Complementary Foods Improvement are associated with better Height-for-Age $Z$ score in Rural Burkina Faso. African Journal of Food Agriculture and Nutritional Development (AJFAND): Volume 8 No. 22008.

26. Sommerfelt, Elizabeth A and Kathryn S (1994) Children's nutritional status. DHS Comparative Studies No. 12. Calverton, Maryland, USA: Macro International Inc.

27. Cogill B (2003) Guide de mesure des indicateurs anthropometriques. Proje d'Assisstance Technique pour La alimentation et la Nutrition. Academie pour le development de L'education, Washington, D.C, 104 pages.

28. Girma W and Genebo T (2002) Determinants of Nutritional Status of Women and Children in Ethiopia. Calverton, Maryland, USA: ORC Marco

29. Baird J, Fisher D, Lucas P, Kleijnen J, Roberts H, et al. (2005) Being big or growing fast: systematic review of size and growth in infancy and later obesity. BMJ 331: 929.

30. Harder T, Bergmann R, Kallischnigg G, Plagemann A (2005) Duration of breastfeeding and risk of overweight: a meta-analysis. Am J Epidemiol 162 397-403. 